\title{
Primitive Sex Chromosomes in Poeciliid Fishes Harbor Simple Repetitive DNA Sequences
}

\author{
INDRAJIT NANDA, MANFRED SCHARTL, JÖRG T. EPPLEN, \\ WOLFGANG FEICHTINGER, AND MICHAEL SCHMID \\ Departments of Human Genetics (I.N., W.F., Mi.S.), and Physiological \\ Chemistry I (Ma.S.), Biocenter, University of Würzburg, W-8700, Würzburg, \\ Department of Molecular Human Genetics, Ruhr-University, Bochum \\ (J.T.E.), Germany
}

\begin{abstract}
The demonstration of the chromosomal mode of sex determination via genetic experiments as well as the absence of heteromorphic sex chromosomes affirm poeciliid fishes as a unique group among vertebrates that are endowed with the most primitive form of sex chromosomes. In many different taxa the evolutionary process involved in the differentiation of advanced sex chromosomes is outlined through sex specifically organized repetitive sequences. In this investigation hydridization of synthetic probes specific to genomic simple repeat motifs uncovers a sex-specific hybridization pattern in certain viviparous fishes of the family Poeciliidae. The hybridization pattern together with specific staining of the constitutive heterochromatin by C-banding reveals heterogamety in males (Poecilia reticulata) as well as in females ( $P$. sphenops). In $P$. velifera, however, C-banding alone fails to unravel the heterogametic status. The female specific W-chromosome can be detected by simple repetitive sequence probes. Therefore, the principal significance of heterochromatization as a means of generating differentiated sex chromosomes is evident. (1) 1993 Wiley-Liss,Inc.
\end{abstract}

In comparison with other vertebrate classes, the cytological observation of structurally distinct sex chromosomes in fishes is somewhat sporadic. Conventional microscopic analysis, in which sex chromosomes are precisely heteromorphic, have succeeded in describing cases of heterogamety of the $\mathrm{XX} / \mathrm{XY}$ and XX/XO types (Ebeling and Chen, '70; Chen, '69), the ZZ/ZW type (Chen and Ebeling, '68) and even multiple sex chromosomes (Uyeno and Miller, '71) in several species of fishes (for details see Ohno, '74; Price, '84). However, prior to the onset of cytogenetic analyses, in several gonochoristic fishes belonging to the family Poeciliidae (Cyprinodontiformes) the existence of either male (Poecilia reticulata, Xiphophorus maculatus) or female (X. maculatus) heterogamety has been inferred from genetic crosses using suitable phenotypic markers (Winge, '22; Kallman, '84). Previous cytogenetic investigations on a number of poeciliid fishes including that on $P$. reticulata have failed to document the heteromorphic sex chromosomes (Prehn and Rasch, '69). Also the probable existence of sex chromosomes has not been convincingly demonstrated from karyological studies on several species of $\mathrm{Xi}$ phophorus (but see Foerster and Anders, '77). In spite of its independent origin in different taxa the features of the molecular mechanism underlying the evolution of chromosomal sex determination are apparently analogous. For example, the $\mathrm{Y}$ or $\mathrm{W}$ chromosomes in most vertebrates become reduced in size and have retained few structural genes. They also acquire a large proportion of heterochromatin and consequently confer to special staining properties in the interphase nucleus. In addition, not only late replicating throughout the S-phase the $\mathrm{Y}$ and $\mathrm{W}$ chromosomes are genetically isolated from the rest of the genome by restricting the exchange of the genetic material with that of the $\mathrm{X}$ and $\mathrm{Z}$ chromosome during meiosis (for reviews see Jablonka and Lamb, '90; Charlesworth, '91). In contrast, the poeciliid sex chromosomes have not been found to display any of these properties and therefore are considered to be in the most primitive stage of developing sex chromosomes as they still resemble functional autosomes carrying many functional genes.

A large part of the $\mathrm{Y}$ or $\mathrm{W}$ chromosomal DNA in most species as revealed by C-banding is constitutively heterochromatic and is usually associated with the presence of highly repetitive DNA (Stefos and Arrighi, '71; John and Miklos, '79). While the analysis of repetitive sequences is of general inter-

Received August 7, 1992; revision accepted September 30, 1992 Address reprint requests to Michael Schmid, Department of Human Genetics, University of Würzburg Biozentrum, Am Hubland, W-8700, Würzburg, Federal Republic of Germany.

(ㅇ 1993 WILEY-LISS, INC. 
est in studies of genome evolution, the distribution of a conserved repetitive sequence initially isolated from a snake, shows close linkage to the heterogametic sex chromosome (Singh et al., ' 81 ; Epplen et al., '82). In previous reports, we analyzed different evolutionary stages of sex chromosomes in poeciliid fishes by means of simple repetitive sequences (Nanda et al., '92). Although, large restriction fragments characterized by presence of simple repetitive sequences served as specific heterogametic markers, cytological evidence for a primitive form of sex chromosomes was only demonstrated in case of $P$. reticulata (Nanda et al., '90). In this report detailed cytological analyses on several other poeciliid fishes are presented. In retrospect, hybridization of informative simple repetitive sequences to the genomic DNA digested with restriction enzymes allowed to correlate the sex-specific hybridization signals to the cytological findings. Briefly, our observations demonstrate that in $P$. reticulata and $P$. sphenops cytologically recognizable $\mathrm{Y}$ or $\mathrm{W}$ chromosome correspond to the sex-specific hybridization as detected by simple repetitive sequence. In $P$. velifera (sailfin molly) as well as in two populations of Xiphophorus the hybridization patterns with simple repeats do not concur with the cytological findings. Hence, accumulation of simple sequences is discussed here in the light of its critical bearing on vertebrate sex chromosome differentiation.

\section{MATERIALS AND METHODS}

\section{Animals}

Adult specimens from both sexes of ornamental strains of Poecilia reticulata (guppy), black molly (Poecilia sphenops, var. melanistica; the entirely black breed is known as the melanistica variant) and sailfin molly (Poecilia velifera) were obtained from local animal dealers. Fishes from the "Laguna Catemaco" population of Xiphophorus helleri and specimens of Xiphophorus maculatus from a population of the "Rio Papaloapan" system were analysed. Founder fish for the stocks (Xiphophorus) were obtained from A. and F. Anders (Gießen, FRG) or K.D. Kallman (New York, NY), respectively. The Xiphophorus strains were bred in closed stocks derived from at least two or three brother-sister matings to minimize intrastrain polymorphism of the sex chromosomes analysed.

\section{Chromosome preparation and staining techniques}

After exposing the animals to a $0.03 \%$ solution of colchicine for $6-10 \mathrm{hr}$, the gills, kidneys and spleen were carefully removed for chromosome prep- aration. The tissues were repeatedly minced in a small drop of hypotonic solution with a fine pair of scissors. The released cells along with the small tissue pieces were collected in a tube and incubated in a hypotonic solution of $\mathrm{KCl}(0.046 \mathrm{M})$ for $45 \mathrm{~min}$ at room temperature. After hypotonic treatment, the cell suspension was centrifuged and fixed with 6-8 $\mathrm{ml}$ of chilled acetic acid:methanol (1:3) solution. After overnight fixation at $4^{\circ} \mathrm{C}$, the fixed material was collected by centrifugation $(400 \mathrm{~g})$, resuspended in a small volume of fresh fixative and then dropped onto precleaned slides and air-dried at room temperature. Chromosome preparations were stained in a $5 \%$ Giemsa solution ( $\mathrm{pH} 6.8$ ) for 5-10 min, rinsed in distilled water, and permanently mounted in Eukitt for conventional chromosome analysis. Staining of constitutive heterochromatin (C-banding) was performed according to the method described by Sumner ('72).

\section{DNA preparation and oligonucleotide hybridization}

Genomic DNA isolation from brain, liver, spleen, and gill was carried out according to Blin and Stafford ('76). DNA was digested with the restriction enzymes Hinfl and AluI according to the manufacturer's recommendation at a ratio of $1 \mu \mathrm{g}$ of DNA to 5 units enzyme overnight at $37^{\circ} \mathrm{C}$ and resolved on $0.7 \%$ horizontal agarose gels in TBE buffer (Maniatis et al., '82). The gels were stained with ethidium bromide, photographed, dry-blotted, and then subjected to denaturation and neutralization for hybridization as described (Schäfer et al., '88). The oligonucleotide probes specific for simple repeats were synthesized on an automated DNA synthesizer (Applied Biosystems 381A, Weiterstadt, FRG) and were end-labelled with $\left[\gamma-\mathrm{P}^{32}\right]$ ATP (Amersham, Branschweig, FRG) in a standard kinase reaction. Hybridizations were carried out for $3-4 \mathrm{hr}$ at $43^{\circ} \mathrm{C}$ for $(\mathrm{GACA})_{4},(\mathrm{CA})_{8},(\mathrm{GT})_{8}$ in $5 \times$ SSPE $(20 \times \mathrm{SSPE}$ is $3 \mathrm{M} \mathrm{NaCl}, 200 \mathrm{mM} \mathrm{NaH}_{2} \mathrm{PO}_{4} \times \mathrm{H}_{2} \mathrm{O}, 20 \mathrm{mM}$ EDTA), $0.1 \%$ sodium dodecyl sulphate (SDS), $10 \mu \mathrm{g} / \mathrm{ml}$ sonicated and denatured Escherichia coli DNA, and $1 \times 10^{6} \mathrm{cpm} / \mathrm{ml}$ of labelled probes. After hybridization gels were washed three times for 30 min each at room temperature in $6 \times \mathrm{SSC}(0.9 \mathrm{M} \mathrm{NaCl}, 90 \mathrm{mM}$ trisodium citrate) followed by a $1 \mathrm{~min}$ wash at the hybridization temperature. Gels were then exposed to Kodak XAR-5 film at room temperature. In situ hybridization with the biotinylated (GACA) 4 oligonucleotide to the chromosome of guppy were performed according to the methods described previously (Nanda et al., '90). 


\section{RESULTS \\ DNA analysis}

DNA from both sexes of the species surveyed was HinfI digested and challenged with several simple repeat probes in the gel. In most cases the informative probe revealed a fingerprint pattern comprising some 15-20 fragments in each digest. Principally two categories of fragments were generated on DNA fingerprint: 1) fragments that appeared to be invariably at the high molecular weight region were always present in one of the sexes but never in the other sex; 2) polymorphic fragments (independent of the sex) in which the number of repeats appeared to differ extensively in different individuals. While the first category of hybridization fragment served as marker for evaluating the heterogametic status, the latter pattern of hybridization with the same probe is not at all surprising as sex specifically conserved sequences are known to cross-hybridize simultaneously with several hypervariable autosomal loci (Ali et al., '86; Traut, '87). Table 1 illustrates the details of the hybridization pattern with several simple repeats in the context of heterogametic sexes. Most conspicuously, in the Poecilia reticulata a single male specific (GACA) 4 signal was observed in all individuals (Fig. 1a) at the high molecular weight region which indicates the existence of a long stretch of simple sequences on the Y chromosome. On the other hand, the probe (GATA) ${ }_{4}$ reveals a Y-chromosome specific signal in certain individuals (data not shown). Thus a stable (monomorphic) as well as a polymorphic locus on the $\mathrm{Y}$ chromosome could be detected in $P$. reticulata. With respect to the heterogamety, the GACA and GATA simple sequences appeared less informative in $P$. sphenops and $P$. velifera. In females of $P$. sphenops prominent sex-specific hybridization in the high molecular weight range predicting the presence of a $\mathrm{W}$ chromosome was obtained with the (GGAT) $)_{4}$ and $(\mathrm{CA})_{8}$ probes. The informative (GGAT) ${ }_{4}$ signal is restricted to the $23 \mathrm{~kb}$ region in females whereas the dimeric repeat $(\mathrm{CA})_{8}$ displays several bands ranging from $8 \mathrm{~kb}$ to extremely high molecular weight range (Fig. 1b). Correspondingly two less prominent but consistent female specific signals were noted with $(G T)_{8}$ in $P$. velifera (Fig. 1c). In comparison with $P$. reticulata and the two other Poecilia species, hybridization of simple repeat probes to the Xiphophorus model system could not allocate specific bands to $\mathrm{Y}, \mathrm{W}$, or X chromosomes. In particular, a population of $X$. maculatus as well as $X$. helleri carrying a definite $Y$ chromosome (genetic marker) exhibited an intense smear signal in males with (GATA) ${ }_{4}$ (data not shown). After a prolonged exposure of the X-ray film, similar smear signal could not be marked in females. Probably the large Y-chromosomal DNA lacking restriction sites are just randomly broken and their separation results in the smear signal.

\section{Cytogenetic analyses}

The evolution of differentiated sex chromosomes often correlates with a significant accumulation of simple repetitive sequences. In some species this consistent occurrence can be visualized by conventional C-banding (Schmid, '83). Accordingly, Cbanding analysis of the somatic chromosomes was performed to correlate the sex specific hybridization observed in poeciliid fishes. Figure 2 displays the C-banded karyotypes for all the five species investigated. The chromosome lengths decrease only slightly from one pair to another. Therefore, in the karyotypes the chromosomes form a continuous series of decreasing size, and their numeration is arbitrary. In accordance to the previous reports, all 23 chromosome pairs in Poecilia species as well as 24 chromosome pairs in Xiphophorus are telocentric. The C-band positive heterochromatin is localized mainly in the pericentromeric region of the chromosomes. Additionally, a very distinct heteromor-

TABLE 1. Summary of sex-specific hybridization patterns as detected by simple repetitive sequences

\begin{tabular}{|c|c|c|c|c|}
\hline Species & $\begin{array}{l}\text { Informative enzymes } \\
\text { and probes }\end{array}$ & & $\begin{array}{l}\text { Heterogametic } \\
\text { status }\end{array}$ & $\begin{array}{l}\text { Approx. range of sex } \\
\text { specific fragments (kb) }\end{array}$ \\
\hline P. reticulata & HinfI/AluI & $\begin{array}{l}(\mathrm{GACA})_{4} \\
(\mathrm{GATA})_{4}{ }^{1}\end{array}$ & $\begin{array}{l}\mathrm{XY} / \mathrm{XX} \\
\mathrm{XY} / \mathrm{XX}\end{array}$ & $\begin{array}{l}>23.0 \\
>23.0\end{array}$ \\
\hline P. sphenops & HinfI/AluI & $\begin{array}{l}(\mathrm{GGAT})_{4} \\
(\mathrm{CA})_{8}\end{array}$ & $\begin{array}{l}\text { ZW/ZZ } \\
\text { ZW/ZZ }\end{array}$ & $\begin{array}{l}15.0,>23.0 \\
>23.0,15.0,8.0\end{array}$ \\
\hline $\begin{array}{l}\text { P. velifera } \\
X . \text { maculatus } \\
\text { (Rio Papaloapan) }\end{array}$ & $\begin{array}{l}\text { HinfI } \\
\text { AluI/Sau3A/ } \\
\text { HaellI }\end{array}$ & $\begin{array}{l}(\mathrm{GT})_{8} \\
(\mathrm{GATA})_{4}\end{array}$ & $\begin{array}{l}\mathrm{ZW} / \mathrm{ZZ} \\
\mathrm{XY} / \mathrm{XX}\end{array}$ & $\begin{array}{l}>23.0,10.0 \\
\text { Smear }\end{array}$ \\
\hline $\begin{array}{l}X . \text { helleri } \\
\text { (Laguna Catemaco) }\end{array}$ & HaeIII & $(\mathrm{GATA})_{4}$ & $\mathrm{XY} / \mathrm{XX}$ & Smear \\
\hline
\end{tabular}

'Y-chromosomal polymorphism. 


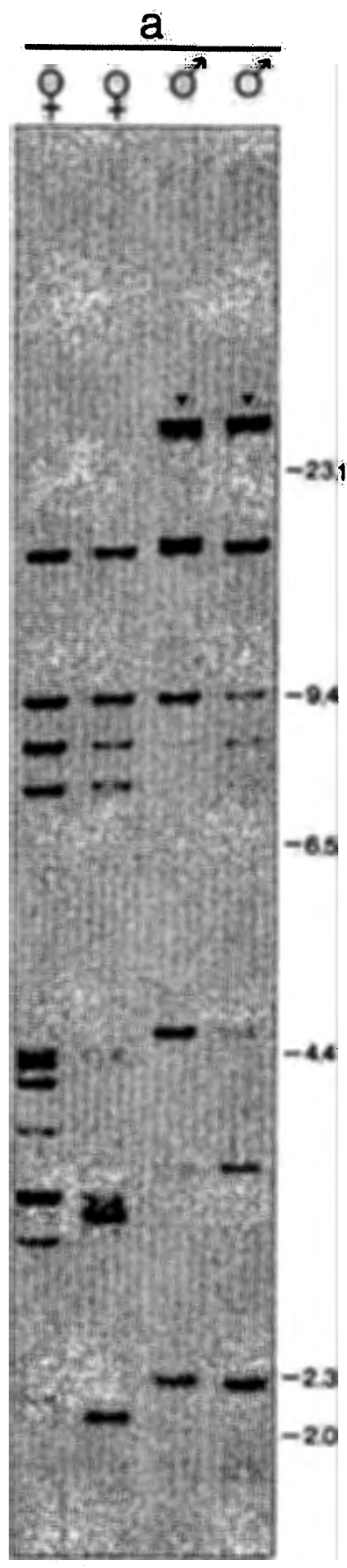

Hinf I, $(\mathrm{GACA})_{4}$

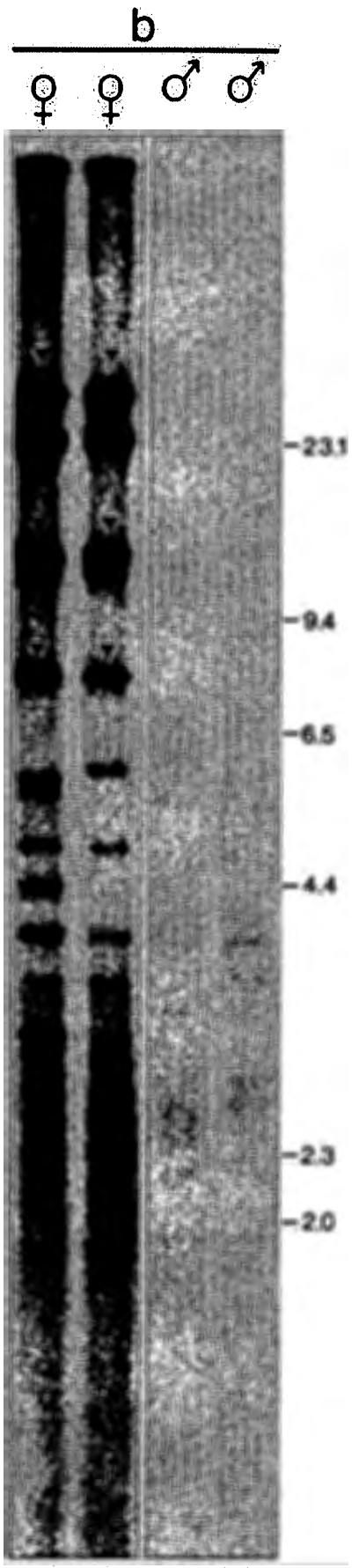

Hinf $I,(C A)_{8}$
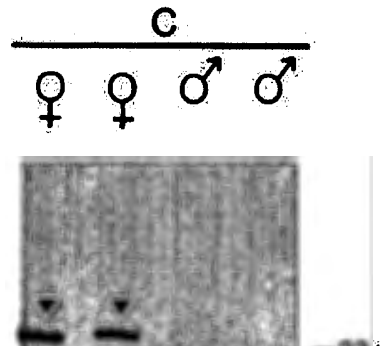

$-231$
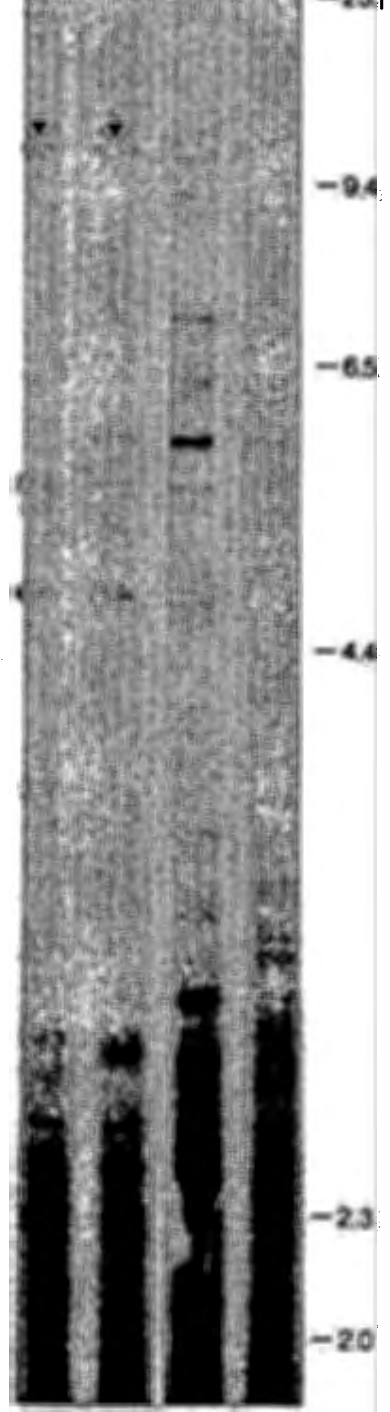

Hinf $I,(G T)_{8}$

Fig. 1. In-gel hybridization of genomic DNA from Poecilia reticulata (a), Poecilia sphenops (b), and Poecilia velifera (c) using the simple repetitive oligonucleotide probes (GACA $)_{4},(\mathrm{CA})_{8}$ and $(G T)_{8}$. Note the sex-specific signals at high molecular weight region. Size markers (HindIIIdigested Lambda DNA) are indicated in kilobases. 


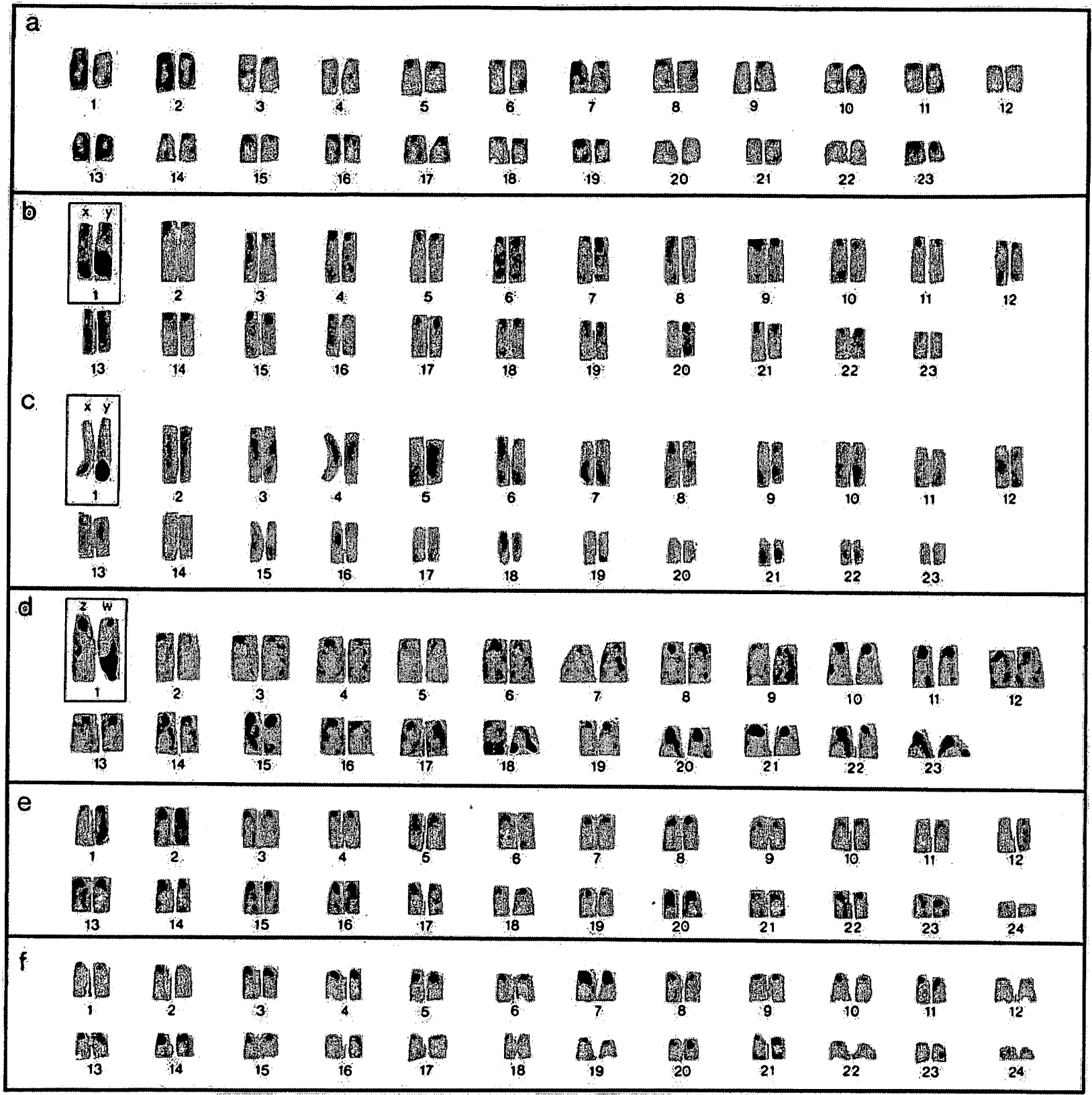

Fig. 2. Karyotypes of (a) Poecilia velifera $\uparrow,($ b,c) P. reticulata $\delta$ (d), P. sphenops $\$$, (e) Xiphophorus helleri $\delta$, and (f) $X$. maculatus $\delta$. a,b,d-f: C-banding. (c) In situ hybridization with a biotinylated (GACA) ${ }_{4}$ oligonucleotide probe. The sex chromosomes are in brackets. Note the prominent telomeric heterochromatin in the $\mathrm{Y}$ and $\mathrm{W}$ chromosomes of (b) $P$. reticulata, (d) $P$. sphenops, and (c) the specific in situ hybridization signal in the $\mathrm{Y}$ chromosome of $P$. reticulata.

phism in the telomeric heterochromatin between two homologous chromosome allows the identification of sex chromosomes in $P$. reticulata and $P$. sphenops. However, the extent of C-band heteromorphism is manifested in a different pattern in both species.

In most of the metaphases of $P$. sphenops the homologous chromosomes of No. 1 pair could be differentiated on the basis of occurrence of telomeric heterochromatin in only one of the homologues in females (Fig. 2d). In the C-banded karyotypes of the male animals these two homologous chromosomes (No. 1) are identical and possess no telomeric heterochromatin (Haaf and Schmid, '84). Therefore 
such a C-band difference leads to the conclusion that these are sex-specific chromosomes of the $\mathrm{ZW}$ $/ \mathrm{ZZ} \delta$ type. Cytologically the only intrinsic difference between the $\mathrm{Z}$ and $\mathrm{W}$ chromosomes is the telomeric heterochromatin. In $P$. reticulata, although both the homologous chromosomes No. 1 carry prominent telomeric heterochromatin, in one of the homologous chromosomes the heterochromatin is apparently more extensive than on the other homologous chromosome in males. Consequently the length of the euchromatic region (C-band negative) is relatively reduced in this particular chromosome (Fig. 2b). By comparing the C-banded preparation between the sexes, there is always distinctly more telomeric heterochromatin on the heterogametic specific $\mathrm{Y}$ chromosome than in the $\mathrm{X}$ chromosome. Furthermore, the sex specific $\mathrm{Y}$ chromosome could be unequivocally identified by hybridizing $(\text { GACA })_{n}$ simple repeat probes in-situ. The hybridization signal always originates from the Y-chromosome heterochromatin, but not from the $\mathrm{X}$ chromosome (Fig. 2c). In contrast to the above observed phenomenon similar heteromorphism could be observed neither in Poecilia velifera nor in the two species of Xiphophorus (Fig. 2a,e,f). Hence the Z(or X) and W(or $\mathrm{Y})$ chromosomes are still structurally identical. Only in fish from the "Laguna Catemaco" population of $X$. helleri, where sex-specific hybridization pattern was marked with (GATA) ${ }_{4}$ inconsistent heterochromatin heteromorphism indicated a small difference between a pair of chromosomes. Larger samples have to be analysed to clarify this phenomenon.

\section{DISCUSSION}

Among most lower vertebrates, simple karyological analysis fails to detect the sex chromosomes, as the $\mathrm{X}$ (orZ) and $\mathrm{Y}$ (orW) chromosomes exhibit equal lengths, the same staining behavior and degree of condensation in conventionally stained preparations. In certain vertebrates, particularly in the colubrid snake Ptyas mucosus or in the hylid frog Rana clamintas, the homomorphic sex chromosomes differ from one another by their C-band character (Singh et al., '76; King, '80). Therefore, heterochromatin staining by C-banding is frequently used to assign the heterogametic status in primitive vertebrates. In fish, heterochromatin analysis in most instances has been performed on already morphologically differentiated sex chromosomes (Galetti and Foresti, '86). Using the C-banding technique alone, the sex chromosomes could be distinguished here on the basis of a higher accumulation of telomeric heterochromatin in $P$. reticulata and
$P$. sphenops and in parallel by the presence of simple repetitive sequences visualized in these chromosomes. Yet, in contrast to the situation in most higher vertebrates the sex chromosomes here are morphologically identical. It can be assumed that the situation in these species may reflect an intermediate stage between truly undifferentiated homomorphic sex chromosomes and highly heteromorphic differentiated sex chromosomes. However, the process which involves the transition of a euchromatic segment on one of the functional homologous chromosomes to cytologically demonstrable, genetically silent heterochromatin in $P$. sphenops cannot be explained satisfactorily. Nevertheless this process might have initiated an effective form of meiotic isolation of the primeval $\mathrm{Z}$ and $\mathrm{W}$ chromosomes.

The analysis of $B$ anded $k$ rait $m$ inor (Bkm) satellite DNA in the snake has allowed us to recover sex-specific sequences which are quantitatively associated with the $\mathrm{W}$ chromosome (Singh et al., '81). Moreover, distribution of this sequence indicates that accumulation of such genomic components coincides with the morphological differentiation of the $\mathrm{W}$ chromosome among snakes. However, in several fishes and in particular amphibians with or without heteromorphic sex chromosomes, the Bkm sequences which are enriched with GATA/GACA simple repeats (Epplen et al., '82) failed to reveal sex-specific hybridization patterns (Lloyd et al., '89; Schmid et al., '91). Conspicuously, these observations suggest that the GATA/GACA simple repeats are probably not the exclusive sequences associated with sex chromosome evolution. In this context, the present investigation on the basis of sex-specific hybrdization patterns as observed in the primitive sex-chromosomes of poeciliid fishes with additional simple repetitive sequences would indicate that several different simple repetitive elements may have accumulated independently on the sex chromosomes. Most notable is the sex-specific hybridization in Xiphophorus and P. velifera where cytologically sex chromosomes can not be detected. Therefore, it is conceivable that accumulation of simple sequences could have preceded the morphological differentiation of sex chromosomes.

The theory pertaining to the evolution of heteromorphic sex chromosomes from an ancestral pair of homologous chromosome (Ohno, '67) that were morphologically identical is convincingly explained by two cytological means: (1) primary heterochromatization where differentiation of the sex-pair actually depends on the heterochromatization event to impede recombination and (2) structural alteration through pericentric inversion (Ohno, '67, Bull, 
'83). The observation on Poeciliid fishes here favors the heterochromatization concept for sex chromosome differentiation. Whether this initial heterochromatization is a cytological manifestation of a process supporting Muller's "ratchet" hypothesis (Muller, '64) or a phenomenon of "hitch-hiking" needs to be discussed. The functional degeneration of the $\mathbf{Y}$ (or W) chromosome through several mutational events ("ratchet") has been conjectured to draw a hypothetical scheme for the evolution of sexchromosomes. In the absence of recombination between the proto-type sex chromosomes the mutational event may have affected the $\mathrm{Y}$ chromosome exclusively (Charlesworth, '78). Therefore it is necessary to analyze whether the accumulation of simple repetitive sequences per se might have functioned as mechanism for suppressing the recombination. Although, classical observations clearly demon. strate that the recombination frequency is extremely low in the heterochromatic region, certain simple sequences are said to be the hot-spot for recombination (Stallings et al., '91). However, it must be mentioned that in most cases intimately interspersed simple sequences are distributed simultaneously on both homologous chromosomes (both alleles). This distribution pattern may itself be the cause of potentiation of recombination. On the other hand the presence of a simple sequence stretch observed here on a single chromosome ( $\mathrm{Y}$ or $\mathrm{W}$ ) would have imposed a qualitative barrier at the sequence level for the recombination to occur and consequently would allow the "ratcheting process" to proceed on the proto-sex chromosomes. Furthermore, in a number of recent studies, simple repetitive DNA sequences have been shown to be the target of nuclear proteins in gel retardation assay systems (Mäueler et al., '92). Therefore the interaction between specific proteins with the simple sequences may be assumed. The implications of this phenomenon on the proto-sex chromosomes of poeciliid fishes are potentially manifold. Specific protein association would allow the $\mathrm{Y}$ (or $\mathrm{W}$ ) chromosome to assume conformational changes that will be lacking on the $\mathrm{X}$ chromosome. Although it is vulnerable to recombine with the $\mathrm{X}$ chromosome, the $\mathrm{Y}$ chromosome's condensed(nascent) state will not allow to open the chromatin sufficiently to undergo recombination with the $\mathrm{X}$ chromosome. However, there is strong evidence which demonstrates the recombination between several homologous genes (or loci) on the poeciliid sex chromosomes. Probably a localized interaction between simple sequences and proteins would allow the sex-determining locus to remain protected from the recombination. Thus the beginning of a process mimicking "hitch-hiking" phenomena can be predicted.

\section{ACKNOWLEDGMENTS}

This work has been supported by the Deutsche Forschungsgemeinschaft (EP 7/6-1, SCHM 484/4-2). The oligonucleotide probes are subjected to patent applications. Commercial enquiries should be directed to Fresenius AG, Oberursel, Germany.

\section{LITERATURE CITED}

Ali, S., C.R. Müller, and J.T. Epplen (1986) DNA fingerprinting by oligonucleotide probes specific for simple repeats. Hum. Genet., 74:239-243.

Blin, N., and D.W. Stafford (1976) A general method for isolation of high molecular weight DNA from eukaryotes. Nucleic Acids Res., 3:2303-2308.

Bull, J.J. (1983) Evolution of Sex Determining Mechanisms. Benjamin/Cumming, Menlo Park, California.

Charlesworth, B. (1978) Model for evolution of Y chromosome and dosage compensation. Proc. Natl. Acad. Sci. USA., 75: 5618-5622.

Charlesworth, B. (1991) The evolution of sex chromosomes. Science, 251:1030-1033.

Chen, T.R., and A.W. Ebeling (1968) Karyological evidence of female heterogamety in the mosquitofish Gambusia affinis (Baird and Girad). Copeia, 1:70-75.

Chen, T.R. (1969) Karyological heterogamety of deep-sea fishes. Postilla, 130:1-29.

Ebeling, A.W., and T.R. Chen (1970) Heterogamety in teleostean fishes. Trans. Am. Fish, 99:131-138.

Epplen, J.T., J.R. Mccarrey, S. Sutou, and S. Ohno (1982) Base sequence of a cloned snake W-chromosome DNA fragment and identification of a male specific putative mRNA in the mouse. Proc. Natl. Acad. Sci. USA., 79:3798-3802.

Foerster, W., and F. Anders (1977) Zytogenetischer Vergleich der Karyotypen verschiedener Rassen und Arten lebendgebärender Zahnkarpfen der Gattung Xiphophorus. Zool. Anzeiger, 198:167-177.

Galetti, P.M., and F. Foresti (1986) Evolution of the ZZ/ZW system in Leporinus (Pisces, Anostomidae): role of constitutive heterochromatin. Cytogenet. Cell Genet., 43:43-46.

Haaf, T., and M. Schmid (1984) An early stage of ZW/ZZ sex chromosome differentiation in Poecilia sphenops var. melanistica (Poeciliidae, Cyprinodontiformes). Chromosoma, 89: $37-41$.

Jablonka, E., and M.J. Lamb (1990) The evolution of heteromorphic sex chromosomes. Biol. Rev., 65:249-276.

John, B., and G.L.G. Miklos (1979) Functional aspects of satellite DNA and heterochromatin. Int. Rev. Cytol., 58:1-114.

Kallman, K.D. (1984) A new look at sex determination in poeciliid fishes. In: Evolutionary genetics of fishes. B.J. Turner, ed. Plenum Press, New York, pp. 95-171.

King, M. (1980) C-banding studies on Australian hylid frogs: secondary constriction structure and the concept of euchromatin transformation. Chromosoma, 80:191-217.

Lloyd, M.A., M.J. Fields, and G.H. Thorgaard (1989) Bkm minisatellite sequences are not sex associated but reveal DNA fingerprint polymorphism in rainbow trout. Genome, 32 : 865-868.

Maniatis, T., E.F. Fritsch, and J. Sambrook (1982) Molecular cloning: A laboratory manual. Cold Spring Harbor Laboratory, Cold Spring Harbor, New York. 
Mäueler, W., M. Muller, A.C. Köhne, and J.T. Epplen (1992) A gel retardation assay system for studying protein binding to simple repetitive DNA sequences. Electrophoresis, 13:7-10.

Muller, H.J. (1964) The relation of recombination to mutational advance. Mutat Res, 1:2-9.

Nanda, I., W. Feichtinger, M. Schmid, J.H. Schröder, H. Zischler, and J.T. Epplen (1990) Simple sequences are associated with differentiation of the sex chromosomes in the guppy fish. $J$. Mol. Evol., 30:456-462.

Nanda, I., M. Schartl, W. Feichtinger, J.T. Epplen, and M. Schmid (1992) Early stages of sex chromosome differentiation in fish as analysed by simple repetitive DNA sequences. Chromosoma, 101:301-310.

Ohno, S. (1967) Sex Chromosomes and Sex Linked Genes Springer, Berlin, Heidelberg, New York.

Ohno, S. (1974) Protochordata, Cyclostomata and Pisces. In: Animal Cytogenetics B. John, ed. Bornträger, Berlin Vol. 4, Chordata 1.

Prehn, L.M., and E.M. Rasch (1969) Cytogenetic studies of Poecilia (Pisces) 1. Chromosome numbers of naturally occurring poeciliid species and their hybrids from Eastern Mexico. Can. J. Genet. Cytol., 11:880-895.

Price, D.J. (1984) Genetics of sex determination in fishes-a brief review. In: Fish reproduction. G.W. Potts and R.J. Wootton, eds. Academic Press, New York, pp. 77-89.

Schäfer, R., H. Zischler, U. Birsner, A. Becker, and J.T. Epplen (1988) Optimized oligonucleotide probes for DNA fingerprinting. Electrophoresis, 9:369-374.
Schmid, M. (1983) Evolution of sex chromosomes and heterogametic systems in Amphibia. Differentiation (Suppl.), 23: 13-22.

Schmid, M., I. Nanda, C. Steinlein, K. Kausch, T. Haaf, and J.T. Epplen (1991) Sex determining mechanisms and sex chromosomes in Amphibia. In: Amphibian cytogenetics and evolution. D.M. Green and S.K. Sessions, eds. Academic Press, New York, pp. 393-430.

Singh, L., I.F. Purdom, and K.W. Jones (1976) Satellite DNA and evolution of sex chromosomes. Chromosoma, 59:43-62.

Singh, L., I.F. Purdom, and K.W. Jones (1981) Conserved sex chromosome associated nucleotide sequences in eukaryotes. Cold Spring Harb Symp. Quant. Biol., 45:805-814.

Stallings, R.L., A.F. Ford, D. Nelson, D.C. Torney, C.E. Hildebrand, and R.K. Moyzis (1991) Evolution and distribution of $(\mathrm{GT})_{\mathrm{n}}$ repetitive sequences in mammalian genomes. Genomics, 10:807-815.

Stefos, K., and F.E. Arrighi (1971) The heterochromatic nature of the W chromosome in birds. Exp. Cell Res., 83:9-14.

Sumner, A.T. (1972) A simple technique for demonstrating centromeric heterochromatin. Exp. Cell Res., 75:304-306.

Traut, W. (1987) Hypervariable Bkm DNA loci in a moth, Ephestia kuehniella: does transposition cause restriction frag ment length polymorphism (RFLP)?. Genetics, 115:493-498.

Uyeno, T., and R.R. Miller (1971) Multiple sex chromosomes in a Mexican Cyprinodontid fish. Nature, 231:452-453.

Winge, O. (1922) One sided masculine and sex linked inheritance in Lebistes reticulatus. J. Genet., 12:145-162. 